\title{
Research on the Influence of Internal Control Quality on the Growth of SMEs
}

\author{
Xiaodan Yang \\ School of Management \\ Henan University of Science and Technology \\ Luoyang, China \\ xiaodan.yang95@qq.com
}

\author{
Baofeng Li \\ School of Management \\ Henan University of Science and Technology \\ Luoyang, China \\ Bfli2008@163.com
}

\begin{abstract}
This study focuses on 2085 companies listed on the small and medium-sized board in 2014-2016. Based on theoretical analysis, the influence of internal control quality on the growth of SMEs is determined by means of empirical research, and whether this influence will change due to the nature of property is further explored. The results show that the internal control quality of SMEs has a positive effect on growth, that is, effective and standardized internal control can enhance the growth of SMEs. Moreover, compared with nationalized businesses, the quality of internal control can influence the growth of non-stateowned enterprises more significantly.
\end{abstract}

Keywords-Internal Control Quality; Growth; Nature of property; SMEs

\section{INTRODUCTION}

According to statistics, as of 2017 , more than $90 \%$ Chinese enterprises were SMEs, and the number was up to 40 million. These enterprises have played a supporting role in promoting employment, improving people's livelihood, enhancing social stability, and strengthening the national economy. However, compared with large enterprises, SMEs have the characteristics of small scale, weak strength, insufficient funds, and lack of sound governance structure, leading to the shorter life cycle and weaker growth. Looking for ways to improve the growth of SMEs has become a key issue concerned by all walks of life. Corporate growth is restricted by various external factors, such as the lack of comprehensive policies, uneven regional development, and lagging regulations. However, a company must start from within the enterprise to achieve long-term development. Internal control plays an important supporting role in the overall operation of an enterprise. Whether the integrity of the system and the quality of its implementation can influence the growth of a company?

At present, scholars from China and foreign countries are concentrating on the short-term influence of Internal Control on enterprises. Few scholars study the long-term influence of Internal Control on enterprises, to be specific, the influence of Internal Control on the Growth of enterprises. Chen Hongming and Shi Yanan et al. (2012) used regression analysis to identify 200 listed manufacturing firms as the observation object. They confirmed on the positive influence of internal control on achieving corporate goals and improving corporate value [1]. Cheng et al. (2013) studied the firms that had disclosed internal control defects, finding that the publicity of these defects can help enterprises to improve investment efficiency. This conclusion provides more direct evidence for the relationship between internal control and investment efficiency [2]. Xie Haijuan et al (2016) pointed out that good internal control can not only improve the effectiveness of working capital management, but also enhance the competitiveness and promote the growth of enterprises [3]. Based on the real options theory, Zhou Zhongsheng (2017) believed that effective Internal Control is beneficial to business operators to better grasp investment opportunities and reduce nonefficiency investment. Good internal control can help enterprises with high profitability to gain option value [4]. By carrying out empirical research, Lin Aimei (2019) found that defects in internal control can lead to a decline in corporate performance and adverse impact on the growth of enterprises. Corporate performance can be significantly enhanced by repairing internal control defects [5]. Zhao Jie (2018) built a framework of Diversification, Internal Control, and Corporate Value. On the basis of empirical research, she found that diversified enterprises with high-quality Internal Control have higher resource allocation efficiency, which can create greater value for enterprises. Moreover, internal control has more obvious effects on non-state-owned diversified businesses [6].

By reviewing the existing research conclusions, it can be found that the quality of internal control has positive influence on the short-term performance of enterprises. This study intends to explore whether the internal control of SMEs will affect their long-term performance based on the existing conclusions, that is, whether it has influence on corporate growth. Based on the relevant data of small and medium-sized listed enterprises in China, this study uses empirical methods to investigate the influence of internal control on corporate growth and reveal the internal influence mechanism. The purpose of this study is to further improve the internal rules and regulations of enterprises, strengthen the focus of operators on Internal Control, and explore how to better enhance the Growth of SMEs.

\section{THEORETICAL ANALYSIS AND RESEARCH HYPOTHESIS}

\section{A. The impact of Internal Control Quality on the Business Growth}

Internal control plays an important role in controlling the overall business process of enterprises. Perfect Internal Control 


\section{RESEARCH DESIGN}

can remove possible obstacles in corporate development by internal environment and activity control, risk assessment, and supervision. High-quality and sound Internal Control alleviates the principal-agent problem caused by information inequality between the owner and the CEO, provides good supervision and incentive signals to all parties, and reduces non-efficiency investment, thereby improving the growth of enterprises. Moreover, Internal Control can enhance the accounting conservatism and improve the comparability of financial reports through the regulation and control of systems and processes, so that shareholders and management can make correct economic decisions, thus promoting the development of enterprises [7]. In addition, effective Internal Control reduces trait risks of companies through precautionary prevention and supervision, strengthens the ability to resist systemic risks, and weakens the impact of unfavorable factors on corporate growth. Based on the above discussion, the following hypothesis is presented:

H1: Under certain other conditions, companies with sound Internal Control have better Growth.

\section{B. The impact of Internal Control Quality on the Growth of enterprises under the different equity nature}

Whether a company can sustain healthy development depends on two factors. One is the opportunity and conditions in the external environment, and the other is the advantages and strengths in the internal environment. Most companies listed on small and medium-sized boards are non-state-owned. Compared with state-owned enterprises, these enterprises do not have the advantage of natural innovation resource and government innovation subsidy. Moreover, these enterprises are restricted by accounting standards. They also have disadvantages in terms of policy support, tax incentives and financing facilities. The external environment has many unfavorable factors for the growth of small-sized non-stateowned enterprises. In the face of the constraints of the external environment, enterprises have to explore more internal breakthroughs to promote continuous expansion. In The Theory of the Growth of The Firm, Penrose proposed that the growth of a company is a process of continuous interaction between management capabilities and resources. The resources here refer to human resources, assets, management capabilities, internal management capabilities, etc. ${ }^{[8]}$. Internal control is an indispensable part of enterprises. The perfection degree of the system and the quality of its execution represent the internal management capability and operational efficiency of enterprises. Non-state-owned enterprises with an unfavorable external environment generally regard the construction and improvement of internal control as the focus of their work. On the basis of the above discussion, the study makes the following hypothesis:

H2: Under certain other conditions, compared with stateowned enterprises, the growth of non-state-owned enterprises is influenced by the quality of Internal Control more significantly.

\section{A. Sample selection and data source}

This study selected the companies listed on small and medium-sized boards in 2014-2016 as the initial research object. On this basis, the following samples were deleted: (1) samples from the financial and insurance industries; (2) samples from ST and *ST in the current year; and (3) Samples with incomplete data. In the end, a total of 2085 samples with research value were obtained. The financial data variables used in this study were collected from CSMAR Database, and DIB Database. The statistics and processing of data were completed by Excel2010 and Spss23.

Internal Control Quality has a hysteresis effect on the Growth of enterprises. In order to avoid interference from endogenous problems, the data representing the explanatory variables from 2015-2017 is selected in this study.

\section{B. Variable definitions}

\section{1) Interpreted variables: Growth}

The growth of a company can reflect its ability to expand in the future. According to previous research, scholars mainly use two methods to measure growth. One is the single indicator method. For example, many scholars use Tobin's Q value and operating income growth rate to represent the Growth. The other is the comprehensive indicator method, which uses multiple indicators to represent the growth of enterprises. Growth can reflect enterprises' comprehensive capabilities. It is not comprehensive enough to use a single indicator to represent the growth of enterprises. Therefore, this study uses current ratio, current asset turnover, total asset growth rate, total asset net profit rate, ROE, operating net profit rate, quick ratio, owner's equity growth rate, total asset turnover rate, asset-liability ratio, asset return rate, asset preservation and appreciation rate to represent the growth of enterprises. Moreover, factor analysis is conducted to extract the common factors of the above indicators, and the comprehensive evaluation index of growth is calculated.

\section{2) Explanatory variables: Internal Control Quality}

This study takes the index from DIB as a substitute to measure the quality of Internal Control. The index, which measures the quality of Internal Control according to the achievement level of the five goals of internal control, has been widely recognized by scholars, like Yang Mingde. The larger the index, the more robust the internal control system of a company, and the more effective the implementation of the system.

\section{3) Control variables}

The growth of enterprises can be influenced by various factors. This study focuses on the influence of Internal Control Quality on Growth. Therefore, it is necessary to control other influencing factors. According to previous literature, this study selects the company size, capital structure, equity concentration, equity balance, and incentive compensation as the control variables. The definitions of the variables are shown in TABLE I. 
TABLE I. VARIABLE DEFINITIONS

\begin{tabular}{|c|c|c|c|}
\hline Variable type & Variable name & Variable symbol & Variable description \\
\hline Explained variable & Business growth & Growth & Factor score \\
\hline Explanatory variables & Internal control quality & IC & The natural logarithm of DIB's internal control index \\
\hline \multirow{4}{*}{ Control variable } & Company Size & Size & Natural logarithm of total assets at the end of the year \\
\cline { 2 - 4 } & Capital Structure & Lev & asset-liability ratio \\
\cline { 2 - 4 } & Equity concentration & Top & The shareholding ratio of the largest shareholder \\
\cline { 2 - 4 } & Equity balance & $\mathrm{Z}$ & The ratio of the shareholding ratio of the first and second-largest shareholders \\
\cline { 2 - 4 } & Incentive compensation & Com & The natural logarithm of the sum of the top three executives' compensation \\
\hline
\end{tabular}

\section{Model setting}

In order to study the influence of internal control quality on the growth of SMEs and the impact of different property rights on their relationship, this study draws on the existing research to establish the following model:

Growth $=\beta_{0}+\beta_{1} I C+\beta_{2}$ Size $+\beta_{3}$ Lev $+\beta_{4}$ Top $+\beta_{5} Z+$ $\beta_{6} \mathrm{Com}+\varepsilon$

$\beta_{0}, \beta_{1_{-}} \beta_{6}$ are the intercept term and coefficients in the multiple regression models, respectively. $\varepsilon$ is the random error term. First, the collated data are substituted into the model to verify hypothesis 1 . According to the nature of the firm, the samples are divided into state-owned enterprises and non-stateowned enterprises. The two sets of data are substituted into the model for the comparison test.

\section{EMPIRICAL ANALYSIS}

\section{A. Factor analysis}

The above 12 financial indicators represent the growth of SMEs, and the factor scores can reflect enterprises' comprehensive capabilities more comprehensively. Moreover,
SPSS 23 is used to perform KMO and Bartlett sphere tests on the sample data. The test results are listed in Table 2. The $\mathrm{KMO}$ value is $0.636>0.5$, and Sig. $=0.000$, less than 0.05 . The test results demonstrate that the selected indicators are more suitable for factor analysis.

TABLE II. KMO AND BARTLETT INSPECTION RESULTS

\begin{tabular}{|c|c|c|}
\hline \multicolumn{3}{|c|}{ KMO and Bartlett's inspection } \\
\hline \multirow{2}{*}{$\begin{array}{c}\text { Kaiser-Meyer-Olkin Measure of Sampling } \\
\text { Adequacy }\end{array}$} & \multicolumn{2}{|c|}{0.636} \\
\hline \multirow{2}{*}{ Bartlett's Test of Sphericity } & $\begin{array}{c}\text { Approx. Chi- } \\
\text { Square }\end{array}$ & 28288.137 \\
\cline { 2 - 3 } & $\mathrm{df}$ & 66 \\
\cline { 2 - 3 } & Sig. & 0.000 \\
\hline
\end{tabular}

Table III shows the eigenvalues, contribution rates, and cumulative contribution rates of the principal components obtained by principal component analysis. The eigenvalues of the four selected common factors are larger than 1 . These four common factors explain 32.685\%, $21.480 \%, 16.608 \%$, and $12.747 \%$ of the overall variance, respectively, and the total variance contribution rate is $83.520 \%$. The four common factors retain more than $80 \%$ of the original data. Therefore, they can better represent the main information of the initial data.

TABLE III. TOTAL VARIANCE EXPLAINED

\begin{tabular}{|c|c|c|c|c|c|c|c|c|c|}
\hline \multirow{2}{*}{ Components } & \multicolumn{4}{|c|}{ Initial eigenvalues } & \multicolumn{3}{c|}{ Extraction sums of squared loadings } & \multicolumn{2}{c|}{ Rotation sums of squared loadings } \\
\cline { 2 - 10 } & Total & Variance//\% & Cumulative//\% & Total & Variance//\% & Cumulative//\% & Total & Variance//\% & Cumulative//\% \\
\hline 1 & 3.922 & 32.685 & 32.685 & 3.922 & 32.685 & 32.685 & 3.503 & 29.193 & 29.193 \\
\hline 2 & 2.578 & 21.480 & 54.165 & 2.578 & 21.480 & 54.165 & 2.420 & 20.166 & 49.359 \\
\hline 3 & 1.993 & 16.608 & 70.773 & 1.993 & 16.608 & 70.773 & 2.200 & 18.333 & 67.692 \\
\hline 4 & 1.530 & 12.747 & 83.520 & 1.530 & 12.747 & 83.520 & 1.899 & 15.828 & 83.520 \\
\hline
\end{tabular}

The score functions F1, F2, F3, and F4 of the observation samples on the four common factors are calculated according to the factor coefficient matrix in Table 4. The ratio of the variance contribution rate after the rotation corresponding to each common factor to the total contribution rate is used as the weight. Finally, the comprehensive score $\mathrm{F}$ of the growth of each observation sample is obtained by using the weighted average method.
$F_{3}=0.004 X_{1}+0.002 X_{2}+0.002 X_{3}+0.013 X_{4}+0.025 X_{5}-0.018 X_{6}$ $-0.035 X_{7}-0.036 X_{8}-0.038 X_{9}+0.404 X_{10}+0.402 X_{11}+0.386 X_{12}$ $F_{4}=0.513 X_{1}+0.524 X_{2}+0.053 X_{3}+0.056 X_{4}-0.019 X_{5}+0.001 X_{6}$ $+0.007 X_{7}+0.005 X_{8}-0.127 X_{9}+0.015 X_{10}-0.028 X_{11}+0.021 X_{12}$ $F=0.3495 F_{1}+0.2415 F_{2}+0.2195 F_{3}+0.1895 F_{4}$

$$
\begin{aligned}
& F_{1}=-0.042 X_{1}-0.039 X_{2}-0.053 X_{3}-0.052 X_{4}-0.015 X_{5}+0.278 X_{6} \\
& +0.284 X_{7}+0.280 X_{8}+0.258 X_{9}-0.023 X_{10}-0.056 X_{11}-0.046 X_{12} \\
& F_{2}=0.032 X_{1}+0.062 X_{2}+0.416 X_{3}+0.413 X_{4}-0.296 X_{5}-0.056 X_{6} \\
& -0.032 X_{7}+0.001 X_{8}+0.001 X_{9}+0.006 X_{10}-0.023 X_{11}+0.006 X_{12}
\end{aligned}
$$


TABLE IV. COMPONENT SCORE COEFFICIENT MATRIX

\begin{tabular}{|c|c|c|c|c|}
\hline & \multicolumn{4}{|c|}{ Components } \\
\cline { 2 - 5 } & $\mathbf{1}$ & $\mathbf{2}$ & $\mathbf{3}$ & $\mathbf{4}$ \\
\hline Current asset turnover $\left(X_{1}\right)$ & -0.042 & 0.032 & 0.004 & 0.513 \\
\hline Total asset turnover $\left(X_{2}\right)$ & -0.039 & 0.062 & 0.002 & 0.524 \\
\hline Current ratio $\left(X_{3}\right)$ & -0.053 & 0.416 & 0.002 & 0.053 \\
\hline Quick ratio $\left(X_{4}\right)$ & -0.052 & 0.413 & 0.013 & 0.056 \\
\hline Debt Assets Ratio $\left(X_{5}\right)$ & -0.015 & -0.296 & 0.025 & -0.019 \\
\hline Return on equity $\left(X_{6}\right)$ & 0.278 & -0.056 & -0.018 & 0.001 \\
\hline Return On Total Assets $\left(X_{7}\right)$ & 0.284 & -0.032 & -0.035 & 0.007 \\
\hline Rate of Return on Total & 0.280 & 0.001 & -0.036 & 0.005 \\
\hline Assets $\left(X_{8}\right)$ & & & & -0.127 \\
\hline Operating net profit margin $\left(X_{9}\right)$ & 0.258 & 0.001 & -0.038 & -0.13 \\
\hline $\begin{array}{c}\text { Asset preservation and } \\
\text { appreciation rate }\left(X_{10}\right)\end{array}$ & -0.023 & 0.006 & 0.404 & 0.015 \\
\hline Total asset growth rate $\left(X_{11}\right)$ & -0.056 & -0.023 & 0.402 & -0.028 \\
\hline Ownership growth rate $\left(X_{12}\right)$ & -0.046 & 0.006 & 0.386 & 0.021 \\
\hline
\end{tabular}

\section{B. Descriptive statistics}

According to the descriptive statistics of each variable in Table 5, the standard deviation of the variables is not large, and the mean is almost the same as the median, indicating the data is relatively stable. The growth scores of the companies vary widely. The minimum value is -2.9839 , the maximum value is 5.5592, the mean is 0 , and the median is negative. Most enterprises listed in the small and medium-sized board have poor growth, and they are in a state of backward development. The scores for Internal Control Quality are significantly different, and the mean is 6.4737 less than the median. The data show that the overall level of internal control of SMEs is uneven, and the companies with weak internal control account for a large proportion.

TABLE V. DESCRIPTIVE STATISTICS

\begin{tabular}{|c|c|c|c|c|c|c|}
\hline Variable & $\mathbf{N}$ & Mean & Median & SD & Minimum & Maximum \\
\hline Growth & 2085 & 0.0000 & -0.044 & 0.5144 & -2.9839 & 5.5592 \\
\hline IC & 2085 & 6.4737 & 6.4908 & 0.1151 & 5.3311 & 6.7865 \\
\hline Size & 2085 & 21.9037 & 21.8172 & 0.8675 & 18.5240 & 25.7051 \\
\hline Lev & 2085 & 0.3777 & 0.3682 & 0.1829 & 0.0091 & 0.9526 \\
\hline Top & 2085 & 0.3340 & 0.3180 & 0.1409 & 0.0431 & 0.8504 \\
\hline Z & 2085 & 6.9672 & 3.2320 & 13.2315 & 1.0000 & 275.1268 \\
\hline Com & 2085 & 14.2448 & 14.2414 & 0.6430 & 11.8494 & 16.8338 \\
\hline
\end{tabular}

\section{Correlation analysis}

According to the analysis results in Table 6, the correlation coefficients between the main variables are less than 0.6. The correlation coefficient between Internal Control Quality and Growth has passed the significance test at the $1 \%$ level, and the value is 0.209 . This initially proves the positive influence of Internal Control Quality on Growth. According to the VIF test results of the variance expansion factor, the VIF values are between 1-2, much lower than the critical value of 10 , and the tolerance is much larger than 0.1 . Therefore, there is no collinearity problem between the main variables.
TABLE VI. CORRELATION COEFFICIENT OF MAIN VARIABLES

\begin{tabular}{|c|c|c|c|c|c|c|c|}
\hline & Growth & IC & Size & Lev & Top & Z & Com \\
\hline Growth & 1 & & & & & & \\
\hline IC & $0.209 * *$ & 1 & & & & & \\
\hline Size & $-0.118^{* *}$ & $0.091^{* *}$ & 1 & & & & \\
\hline Lev & $-0.339^{* *}$ & $-0.080^{* *}$ & $0.512^{* *}$ & 1 & & & \\
\hline Top & $0.098^{* *}$ & $0.073^{* *}$ & $0.062^{* *}$ & 0.036 & 1 & & \\
\hline Z & -0.008 & 0.010 & $0.051^{*}$ & $0.072^{* *}$ & $0.442^{* *}$ & 1 & \\
\hline Com & $0.094^{* *}$ & $0.155^{* *}$ & $0.415^{* *}$ & $0.085^{* *}$ & 0.024 & -0.036 & 1 \\
\hline
\end{tabular}

\section{Regression analysis}

\section{1) Internal Control Quality and Growth}

The test results of hypothesis 1 are shown in Table 7 . From the results, the coefficient of internal control quality in the regression equation is 0.716 , and the coefficient is significant at the $1 \%$ level, demonstrating that the Internal Control of a company has a significantly positive effect on its growth. To be specific, effective and standardized Internal Control can enhance corporate growth, which is consistent with theoretical analysis results. Perfect internal control can constrain corporate initiatives, so that enterprises will not deviate from the track, thus achieving the purpose of promoting corporate growth. Hypothesis 1 is established.

The capital structure has a significant negative effect on corporate growth. The extremely high asset-liability ratio is likely to affect the enthusiasm of investors, thus leading to the lack of funds for development and ultimately limiting corporate growth. The improper capital structure of a company will increase its probability of falling into a financial crisis, which will negatively influence corporate growth. Equity concentration and compensation incentives have been proven to positively promote corporate growth.

TABLE VII. REGRESSION RESULTS OF INTERNAL CONTROL QUALITY AND GROWTH

\begin{tabular}{|c|c|c|c|c|}
\hline \multirow{2}{*}{ Variable } & \multirow{2}{*}{ Coefficient } & \multirow{2}{*}{$\mathbf{t}$} & \multicolumn{2}{|c|}{ Collinear statistics } \\
\hline & & & Tolerance & VIF \\
\hline Cons & $-5.410 * *$ & -8.719 & & \\
\hline IC & $0.716^{* *}$ & 7.820 & 0.954 & 1.048 \\
\hline Size & -0.004 & -0.288 & 0.592 & 1.689 \\
\hline Lev & $-0.934 * *$ & -13.917 & 0.704 & 1.420 \\
\hline Top & $0.403 * *$ & 4.930 & 0.799 & 1.252 \\
\hline $\mathrm{Z}$ & -0.001 & -1.384 & 0.799 & 1.252 \\
\hline Com & $0.077^{* *}$ & 4.285 & 0.793 & 1.260 \\
\hline $\mathrm{N}$ & \multirow{4}{*}{\multicolumn{4}{|c|}{$\begin{array}{c}2085 \\
69.420^{* *} \\
0.167 \\
0.165\end{array}$}} \\
\hline $\mathrm{F}$ & & & & \\
\hline R2 & & & & \\
\hline Adi.R2 & & & & \\
\hline
\end{tabular}

Note: **, * respectively indicate that the correlation coefficient is significant at $1 \%, 5 \%$ level (both sides).

2) The impact of internal control quality on the growth of enterprises under the different equity nature

In order to explore whether the nature of equity affects the relationship between Internal Control Quality and Growth in listed companies, this study divides 2085 samples into the state-owned enterprise group (320) and the non-state-owned enterprise group (1765). The two sets of data are substituted 
into the model for testing, and the test results are shown in Table 8. The Goodness of Fit of the multiple regression equations of the state-owned enterprise group and the nonstate-owned enterprise group are $30.5 \%$ and $15.2 \%$, respectively. This indicates that the overall explanatory power of the model is strong, and the model passes the significance test at the level of $1 \%$. The established model is valid. By comparing the two sets of data, the coefficient of Internal Control Quality of the state-owned enterprise group is 0.189 . The improvement of internal control can promote the growth of an enterprise, but it has not passed the significant test. The coefficient of Internal Control Quality in the non-state-owned enterprise group is 0.797, and the coefficient passes the significance test at the level of $1 \%$. From the above results, we can see that the quality of internal control has a significant influence on the growth of non-state-owned enterprises. Hypothesis 2 has been verified.

TABLE VIII. RESULT OF GROUP TEST

\begin{tabular}{|c|c|c|c|c|}
\hline \multirow{2}{*}{ Variable } & \multicolumn{2}{|c|}{ State-owned enterprise } & \multicolumn{2}{|c|}{ Non-state-owned enterprise } \\
\hline & Coefficient & $t$ & Coefficient & $t$ \\
\hline Cons & $-3.584 * *$ & -2.931 & $-5.645^{* *}$ & -8.115 \\
\hline IC & 0.189 & 1.017 & $0.797 * *$ & 7.811 \\
\hline Size & 0.022 & 0.782 & -0.010 & -0.574 \\
\hline Lev & $-1.024 * *$ & -8.292 & $-0.885^{* *}$ & -11.467 \\
\hline Top & 0.244 & 1.541 & $0.449 * *$ & 4.857 \\
\hline $\mathrm{Z}$ & 0.000 & -0.253 & -0.001 & -0.967 \\
\hline Com & $0.149 * *$ & 4.306 & $0.064 * *$ & 3.154 \\
\hline $\mathrm{N}$ & \multicolumn{2}{|c|}{320} & \multicolumn{2}{|c|}{1765} \\
\hline $\mathrm{F}$ & \multicolumn{2}{|c|}{$22.888 * *$} & \multicolumn{2}{|c|}{$52.664 * *$} \\
\hline $\mathrm{R} 2$ & \multicolumn{2}{|c|}{0.305} & \multicolumn{2}{|c|}{0.152} \\
\hline Adi.R2 & \multicolumn{2}{|c|}{0.292} & \multicolumn{2}{|c|}{0.149} \\
\hline
\end{tabular}

\section{E. Robustness test}

This study uses a single total asset growth rate to represent the growth of SMEs to ensure the reliability of the regression results. The data is further substituted into the model for regression analysis, and the test results are consistent with the previous conclusions. Therefore, the conclusion of this study is reliable.

\section{CONCLUSIONS AND RECOMMENDATIONS}

This paper took 2085 China's small and medium-sized companies listed in 2014-2016 as the research object. Empirical methods were used to explore the relationship between internal control and corporate growth, and whether the nature of equity can influence the relationship was further discussed. The conclusions of this study are as follows: (1) The quality of Internal Control of SMEs has an obvious positive effect on Growth. Under certain other condition, corporate growth will be promoted with the improvement of internal control. (2) Compared with state-owned enterprises, the quality of Internal Control can influence the Growth of non-stateowned enterprises more significantly.

The conclusions provide for powerful support for the indepth implementation of the internal control construction and render valuable inspiration for improving corporate growth and achieving sustainable development. (1) Implement the reward and punishment system to improve the emphasis and autonomy of the operators on Internal Control. The institutions of most firms are doing not play a real role. Executives have not realized the long-term significance of Internal Control. Therefore, enterprises should link the assessment of internal control quality with the performance appraisal of senior executives, and formulate a reasonable and effective reward and punishment system, which can not only mobilize the autonomy and enthusiasm of various departments in internal control but also improve the overall construction of enterprises. (2) Strengthen the supervision of internal control and establish a sound internal control evaluation system. In this way, the relevant personnel is guaranteed to make an independent and objective evaluation to ensure the reliable, independent and true evaluation of internal control quality. Enterprises should increase the transparency of internal control information and weaken the information inequality between enterprises and information users, so as to achieve sustainable growth.

\section{REFERENCES}

[1] Hongming Chen, Yanan Shi. Empirical Study on the Correlation between Internal Control and Enterprise Value-Based on the Information System, 7th ed., vol. 7. Journal of Computers, 2012, pp. 1387-1396.

[2] M. Cheng, D. Dhaliwai, and Y.Zhang. Does Investment Efficiency Improve after the Disclosure of Material Weaknesses in Internal Control over Financial Reporting, 1st ed., vol.56. Journal of Accounting and Economics, 2013, pp. 1-18.

[3] Xie Haijuan, Liu Xiaotong, Wang Xinxue. The Impact of Internal Control Effectiveness on the Effect of Working Capital Management, 6th ed., Finance and Accounting Monthly, 2016, pp. 70-76. (In Chinese)

[4] Zhou Zhongsheng, Luo Zhengying, Zhou Xiuyuan, Shenyang. Internal Control, Enterprise Investment and Company Option Value! , 12th ed., Accounting Research, 2017, pp.38- 44, 96. (In Chinese)

[5] Lin Aimei, Chen Mengdi. The Influence of Internal Control Defects and Defect Repair on Firm Performance-Analysis of the Adjustment Effect Based on Social Trust, 6rd ed., Friends of Accounting, 2019, pp.63-68. (In Chinese)

[6] Zhao Jie. Diversification, Internal Control, Corporate Value, 8th ed., Friends of Accounting, 2018, pp. 26- 31. (In Chinese)

[7] Zhang Xiangzhi, Liu Kunpeng, Li Qinghua. Strategic Deviation, Internal Control Quality and Financial Report Comparability, 6th ed., Audit and Economic Research, 2018, pp. 35- 47. (In Chinese)

[8] E.T. Penrose, the Theory of the Growth of the Firm, John Wiley, New York, 1959. 